\title{
Pituitary Adenylate Cyclase-Activating Peptide in the Central Amygdala Causes Anorexia and Body Weight Loss via the Melanocortin and the TrkB Systems
}

\author{
Attilio lemolo ${ }^{1,2}$, Antonio Ferragud ${ }^{1,2}$, Pietro Cottone ${ }^{*, 1,2,3}$ and Valentina Sabino*,1,2,3 \\ 'Laboratory of Addictive Disorders, Department of Pharmacology and Experimental Therapeutics, Boston University School of Medicine, Boston, \\ MA, USA; ${ }^{2}$ Department of Psychiatry, Boston University School of Medicine, Boston, MA, USA
}

\begin{abstract}
Growing evidence suggests that the pituitary adenylate cyclase-activating polypeptide (PACAP)/PACI receptor system represents one of the main regulators of the behavioral, endocrine, and autonomic responses to stress. Although induction of anorexia is a well-documented effect of PACAP, the central sites underlying this phenomenon are poorly understood. The present studies addressed this question by examining the neuroanatomical, behavioral, and pharmacological mechanisms mediating the anorexia produced by PACAP in the central nucleus of the amygdala (CeA), a limbic structure implicated in the emotional components of ingestive behavior. Male rats were microinfused with PACAP ( $0-1 \mu$ g per rat) into the CeA and home-cage food intake, body weight change, microstructural analysis of food intake, and locomotor activity were assessed. Intra-CeA (but not intra-basolateral amygdala) PACAP dose-dependently induced anorexia and body weight loss without affecting locomotor activity. PACAP-treated rats ate smaller meals of normal duration, revealing that PACAP slowed feeding within meals by decreasing the regularity and maintenance of feeding from pellet-to-pellet; postprandial satiety was unaffected. Intra-CeA PACAP-induced anorexia was blocked by coinfusion of either the melanocortin receptor 3/4 antagonist SHU 91 I 9 or the tyrosine kinase B (TrKB) inhibitor k-252a, but not the CRF receptor antagonist D-Phe-CRF $(|2-4|)$. These results indicate that the $\mathrm{CeA}$ is one of the brain areas through which the PACAP system promotes anorexia and that PACAP preferentially lessens the maintenance of feeding in rats, effects opposite to those of palatable food. We also demonstrate that PACAP in the CeA exerts its anorectic effects via local melanocortin and the TrKB systems, and independently from CRF.
\end{abstract}

Neuropsychopharmacology (20I5) 40, I846-I855; doi:I0.I038/npp.20I5.34; published online 4 March 20 I5

\section{INTRODUCTION}

Food intake regulation is achieved through a complex coordination of peripheral signals and central regulatory circuitry (Kalra et al, 1999). These processes control the initiation, cessation, magnitude, composition and frequency of meals, as well as the long-term regulation of food intake vis-a-vis the body energy necessity (Morton et al, 2006; Woods et al, 1998).

The majority of the studies of ingestive behavior have focused on the hypothalamus as the main brain area involved in the control of food intake and energy balance (Leibowitz and Wortley, 2004). However, many other regions of the central nervous system are involved in the regulation of energy balance; the role of limbic structures in ingestive behavior has indeed been known for a long time. The amygdala, in particular,

* Correspondence: Professor V Sabino or Professor P Cottone, Laboratory of Addictive Disorders, Department of Pharmacology and Experimental Therapeutics, Boston University School of Medicine, 72 East Concord Street, Boston, MA 021।8 USA, Tel: + | 6176384327 , Fax: + 617638 5668, E-mail: vsabino@bu.edu or cottone@bu.edu ${ }^{3}$ These authors contributed equally to the work.

Received 10 December 2014; revised 10 January 2015; accepted II January 2015; accepted article preview online 4 February 2015 which projects both directly and indirectly to the hypothalamus, is becoming of great interest for its role in the regulation of feeding and energy homeostasis (King et al, 1997; Will et al, 2004). The central nucleus of the amygdala $(\mathrm{CeA})$, considered part of the 'limbic' taste pathway, mediates the processing of emotional (rewarding and aversive) properties of stimuli including foods and may modulate hypothalamic activity by coupling sensory/affective processes to metabolic states (Kishi and Elmquist, 2005). The CeA, indeed, plays a key role in the non-homeostatic regulation of feeding and the regulation of macronutrient selection (King et al, 1998; Will et al, 2004). Rats with ablation of the CeA display a reduction in body weight as well as lower preferences for tasty solutions (Touzani et al, 1997), and the activation/inhibition of specific neuropeptide/hormone receptors or cell types within the CeA has been shown to modulate food intake, especially if palatable (Boghossian et al, 2009; Primeaux et al, 2006). The CeA has also recently been implicated in excessive eating (Iemolo et al, 2013).

The pituitary adenylate cyclase-activating polypeptide (PACAP), a 38-amino acid neuropeptide belonging to the secretin glucagon vasoactive intestinal polypeptide (VIP) family, exerts its effects through the activation of three receptors: PAC1 receptor, which binds PACAP with a 1000-fold higher 
affinity than VIP, and VPAC1 and VPAC2 receptors, which bind both PACAP and VIP with similar affinity (Vaudry et al, 2009). PACAP and its receptor PAC1 are highly expressed in the hypothalamus as well as in various extra-hypothalamic regions including the CeA (Joo et al, 2004; Piggins et al, 1996). The PACAP/PAC1 system is believed to play a key role in the regulation of feeding and energy homeostasis (Dore et al, 2013; KochoSchellenberg et al, 2014; Mounien et al, 2009; Resch et al, 2013). Although induction of anorexia is a well-documented effect of PACAP, the central sites and the mechanism underlying this phenomenon are poorly understood. In addition, while PACAP activity in the hypothalamus and the pituitary has been reasonably well-studied, few studies have investigated the functions of the extrahypothalamic PACAP systems.

In this context, the melanocortin system, and in particular the receptor 4 (MC4R), has been implicated in both the acute regulation of satiety and feeding behavior and in the integration of long-term appetitive signals (Seeley et al, 2004). Blockade or absence of MC4R induces hyperphagia, reduced energy expenditure and obesity (Balthasar et al, 2005; Butler and Cone, 2003). Interestingly, MC4R are expressed not only in the hypothalamus but also in the amygdala (Mountjoy et al, 1994); melanocortin signaling in the CeA can indeed regulate feeding behavior bidirectionally, with MC4R exerting a tonic inhibitory role on feeding (ie, producing anorexia) (Boghossian et al, 2010; Kask et al, 2000a).

The present study examines the mechanisms of the anorexia produced by PACAP in the CeA, a limbic structure deeply involved in ingestive behavior, as discussed above. In addition, the potential involvement of the melanocortin system in CeA PACAP-induced hypophagia was explored, which was previously shown to occur at the hypothalamic level (Mounien et al, 2009). Interestingly, the brain-derived neurotrophic factor (BDNF) and its high-affinity receptor, tropomyosin-related kinase receptor type B (TrkB), contribute to the control of food intake, and BDNF has previously been implicated as a probable downstream effector of melanocortinergic signaling in the ventromedial (VMH) hypothalamus. Therefore, we also tested the hypothesis that the TrkB system within the CeA could mediate the actions of PACAP on food intake.

\section{MATERIALS AND METHODS}

\section{Subjects}

Male Wistar rats, 301-325 g at arrival (Charles River, Wilmington, MA), were housed in a $12: 12 \mathrm{~h}$ reverse light cycle (lights off at 0900 hours) AAALAC-approved vivarium. Rats had access to corn-based chow and water ad libitum unless otherwise specified. The number of rats for each experiment was as follows: dose-response studies, $n=11$ (CeA) and $n=8$ (BlA); motor activity, $n=9$; meal microstructure, $n=8$; SHU 9119 blockade, $n=11$; k252a blockade, $n=9$; D-Phe-CRF(12-41) blockade, $n=15$. Procedures adhered to the National Institutes of Health Guide for the Care and Use of Laboratory Animals and the Principles of Laboratory Animal Care, and were approved by BUMC Institutional Animal Care and Use Committee (IACUC).
Drugs

PACAP (PACAP-38) was purchased from the American Peptide Company (Sunnyvale, CA); SHU-9119 was purchased from R\&D Systems (Minneapolis, MN); k252a was purchased from Alomone Labs (Jerusalem, Israel); D-Phe-CRF(12-41) was synthesized by The Clayton Foundation Laboratories for Peptide Biology and kindly provided by Dr Jean Rivier (The Salk Institute for Biological Studies, La Jolla, CA). Doses were given within-subject in a Latin square design with at least three intervening treatment-free days. Drugs were dissolved in isotonic saline with $1 \%$ bovine serum albumin, except for $\mathrm{k} 252 \mathrm{a}$, which was dissolved in 50\% DMSO in saline. The choice of doses was based on previously published studies. PACAP doses were chosen based on those used by us and others in i.c.v. studies, as well as in intra-BNST and intrahypothalamus (Dore et al, 2013; Kocho-Schellenberg et al, 2014; Mounien et al, 2009; Resch et al, 2011); the dose of SHU 9119 were chosen based on previous studies (Blouet et al, 2009; Cheng et al, 2011; Mounien et al, 2009); the doses of $\mathrm{k} 252 \mathrm{a}$ and D-Phe-CRF(12-41) were selected based on pilot experiments and previous studies (Erb and Stewart, 1999; Funk et al, 2006; Ou and Gean, 2006; Ou et al, 2010). PACAP and antagonists were administered as a cocktail in a single injection and at a volume of $0.5 \mu \mathrm{l}$ per side. Drug pretreatment time was $30 \mathrm{~min}$ in all experiments.

\section{Intracranial Surgeries, Microinfusion Procedure, and Cannula Placement}

Intracranial surgeries. Rats were stereotaxically implanted with bilateral cannulas as described previously (Cottone et al, 2007a; Sabino et al, 2007). The coordinates from bregma were: (CeA) $\mathrm{AP}-2.64, \mathrm{ML} \pm 4.2, \mathrm{DV}-6.2$ (from skull); (BlA): AP $-2.64, \mathrm{ML} \pm 4.8, \mathrm{DV}-6.5$ (from skull). Figures $1 \mathrm{~d}$ and $2 \mathrm{~d}$ are photomicrographs showing representative injection sites in the $\mathrm{CeA}$ and $\mathrm{BlA}$, respectively.

Microinfusion procedure. Drugs were microinfused as previously described (Blasio et al, 2014; Dore et al, 2013; Iemolo et al, 2013). The injector projected $2 \mathrm{~mm}$ beyond the tip of the guide cannula. Microinfusions were $0.5 \mu$ l volume per side delivered over $2 \mathrm{~min}$; injectors were left in place for 1 additional min to minimize backflow. For additional information please see Supplementary Materials and Methods.

\section{Home Cage Food Intake and Body Weight Determinations}

Pre-weighed food was provided at the beginning of the dark cycle and recorded 1, 3, 6, and 24 h later. Rat body weights were assessed before drug administration and $24 \mathrm{~h}$ later.

\section{Meal Pattern, within Meals Microstructure, and Return Map Analyses}

Apparatus. To study the microstructure of ingestion, rats were individually housed during the $12 \mathrm{~h}$ of their active dark cycle in Plexiglas test cages $(30 \times 24 \times 29 \mathrm{~cm})$ (VelazquezSanchez et al, 2014). Rats obtained nosepoke-contingent food and water on a fixed ratio 1 (FR1) continuous schedule of reinforcement. About $45 \mathrm{mg}$ pellets (5TUM diet, 65.5\% (kcal) 
a

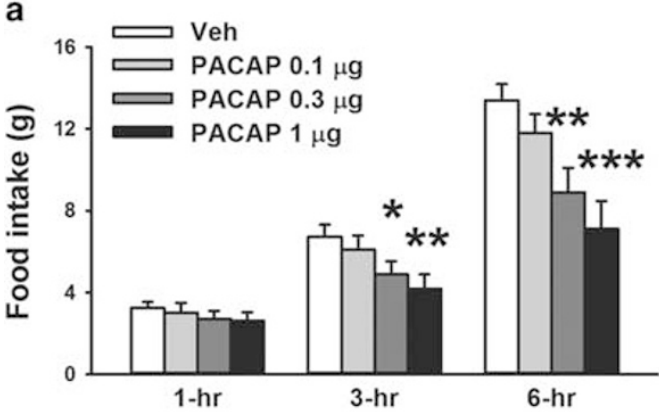

C

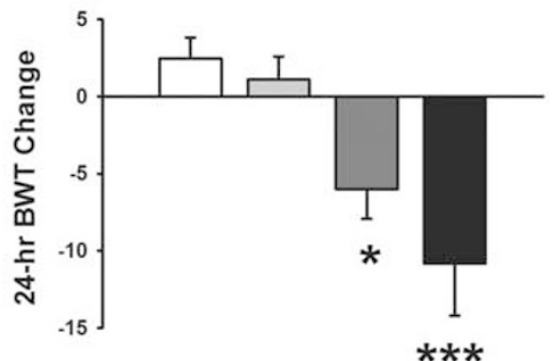

b

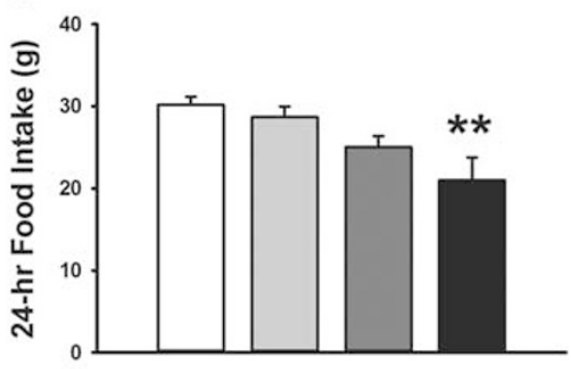

d

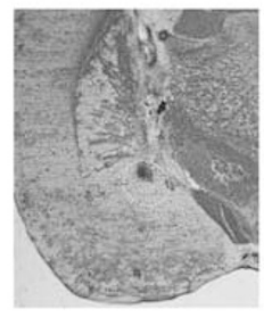

Figure I Effects of bilateral microinfusion of PACAP (0-I $\mu$ g per rat) in the central nucleus of the amygdala (CeA) on (a) I-, 3-, and 6-h food intake, (b) 24-h food intake and (c) 24-h body weight change in male Wistar rats $(n=11)$. Data represent mean \pm SEM. $* p \leqslant 0.05$, *** $p \leqslant 0.01$, **** $p \leqslant 0.00$ I vs vehicle group. (d) The photomicrograph shows a coronal section of the brain of a rat with a representative injection site in the CeA. PACAP, pituitary adenylate cyclase-activating polypeptide.

a
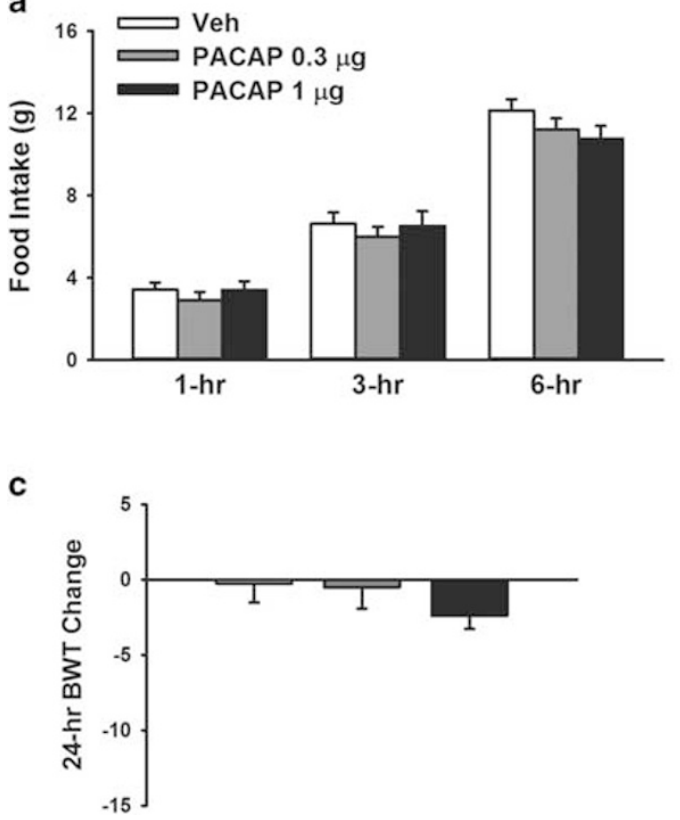

b

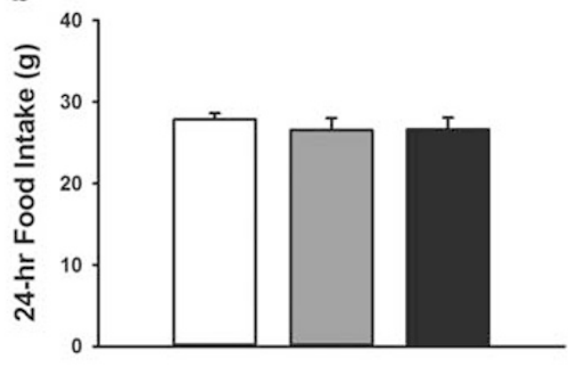

d

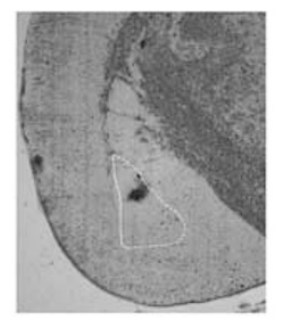

Figure 2 Effects of bilateral microinfusion of PACAP (0-1 $\mu$ g per rat) in the basolateral nucleus of the amygdala (BIA) on (a) I-, 3- and 6-h food intake, (b) 24-h food intake and (c) 24-h body weight change in male Wistar rats $(n=1 \mathrm{I})$. Data represent mean \pm SEM. (d) The photomicrograph shows a coronal section of the brain of a rat with a representative injection site in the BIA. PACAP, pituitary adenylate cyclase-activating polypeptide.

carbohydrate, $10.4 \%$ fat, $24.1 \%$ protein, metabolizable energy $330 \mathrm{kcal}$ per $100 \mathrm{~g}$; TestDiet, Richmond, IN) were delivered from an automated dispenser (Med Associates, St Albans VT), and water reinforcers $(0.1 \mathrm{ml})$ were delivered by a solenoid into a liquid cup nosepoke receptacle. Testing began once food intake had stabilized $(<15 \%$ variation across 3 consecutive days); PACAP (0, $1 \mu \mathrm{g}$ per rat) was administered
30 min prior to dark cycle onset, which corresponded to the beginning of the food self-administration session.

Meal pattern analysis. Microstructure analysis was performed as previously described (Cottone et al, 2007b; Zorrilla et al, 2005). Meals were defined as consecutive responses for 
food or water that contained at least five food-directed responses and in which responses occurred within 5 min of the previous response. Meal size for eating was calculated as the average number of food-directed responses during meals, and duration of eating within the meal as the sum of the durations of bursts of eating. The inter-meal interval was defined as the interval from the last response of a meal to the first response of the next meal. The eating rate was calculated by dividing each meal size by its respective duration.

Within-meal microstructure analysis. To identify the effects of PACAP on the rate and regularity of sustained eating within meals, analysis of the ln-transformed duration of consecutive (uninterrupted by drinking) within-meal interfeeding intervals (IFIs) was performed (Cottone et al, 2007a; Cottone et al, 2012). Histograms were constructed from ln-transformed IFI durations that fell from $e^{-1}$ to $e^{3} \mathrm{~s}(\sim 0.4-$ $20.1 \mathrm{~s}$ ), with a bin width of $e^{0.2}$ (Cottone et al, 2007a; Cottone et al, 2012). The mean, entropy kurtosis, and skewness of the ln-transformed duration of each subject's consecutive IFIs were individually determined and averaged across subjects. The normalized frequency histogram entropy $(H)$ is a measure of categorical variability in the rate of ingestion.

Return map analysis. Return maps, or joint inter-event interval plots, are a nonlinear method of time series analysis that reveals the serial temporal organization of discrete events in time (Dekhuijzen and Bagust, 1996; Szucs et al, 2003). For return map analysis, each IFI in the time-series was scatterplotted against its subsequent inter-feeding interval (IFI+1) in a Cartesian plane. Joint probability density distributions were constructed from return maps and appear in gray scale format with darker shades, indicating higher local probabilities (or a color-coded form with warmer colors (toward red), indicating higher local probabilities in the color figure). For additional information please see Supplementary Materials and Methods.

\section{Motor Activity}

Motor activity of rats in a familiar environment (home cage) was measured as described in (Dore et al, 2013) using an Opto-M3 activity system (Columbus Instruments, Columbus, $\mathrm{OH})$.

\section{Statistical Analysis}

All studies were performed within-subject. PACAP doseresponse curve data at 1,3 and $6 \mathrm{~h}$, and motor activity data were analyzed using two-way repeated measure analyses of variance (ANOVAs) with time and PACAP dose as withinsubject factors; $24-\mathrm{h}$ food intake and body weight change were analyzed using one-way repeated measure ANOVAs with PACAP dose as a within-subject factor. Meal microstructure analyses were performed using Wilcoxon matched pairs tests. Data from the blockade experiments were analyzed using two-way repeated measure ANOVAs with PACAP and antagonist as within-subject factors. Pairwise post-hoc comparisons were made using Newman-Keuls test. Significance was set at $p \leqslant 0.05$. The software/graphic packages used were Systat 11.0, SigmaPlot 11.0, InStat 3.0, and Statistica 7.0.

\section{RESULTS}

\section{Administration of PACAP into the CeA Produces Anorexia and Body Weight Loss}

As shown in Figure 1a, bilateral PACAP administration into the CeA dose-dependently reduced food intake during the 6$h$ post administration (PACAP: $\mathrm{F}(3,30)=10.73, p \leqslant 0.001$; Time: $\mathrm{F}(2,20)=15.85, p \leqslant 0.001$; PACAP X Time: $\mathrm{F}(6,60)=$ 1.79 , NS). While food intake was unaffected during the first hour, post-hoc comparisons revealed that the 0.3 and $1 \mu \mathrm{g}$ dose of PACAP significantly reduced 3- and 6-h food intake ( $3 \mathrm{~h}$ : $-27.3 \%$ and $-37.74 \% ; 6 \mathrm{~h}$ : $-33.5 \%$ and $46.9 \%$, $0.3 \mu \mathrm{g}$ and $1 \mu \mathrm{g}$ respectively, compared with the vehicletreated group).

The $1 \mu \mathrm{g}$ dose of intra-CeA PACAP produced anorexia also at the 24 -h time point $(\mathrm{F}(3,30)=7.23, p \leqslant 0.001)$, as shown in Figure 1b. PACAP-induced anorexia was accompanied by a dramatic body weight loss $24 \mathrm{~h}$ after administration $(\mathrm{F}(3,30)=9.04, p \leqslant 0.001)$, as shown in Figure $1 \mathrm{c}$.

\section{Administration of PACAP into the BlA Does Not Affect Food Intake or Body Weight}

As shown in Figure 2a, bilateral PACAP administration into the $\mathrm{BlA}$ did not reduce food intake during the $6 \mathrm{~h}$ post administration (PACAP: $\mathrm{F}(2,14)=1.40$, NS; Time: $\mathrm{F}(2,14)=$ $9.09, p \leqslant 0.05$; PACAP X Time: $\mathrm{F}(4,28)=0.86, \mathrm{NS})$. Intra-BlA PACAP was still without effect on food intake $24 \mathrm{~h}$ after administration $(\mathrm{F}(2,14)=0.79$, NS) or the body weight change $(F(2,14)=0.90$, NS), as shown in Figure $2 b$ and $c$, respectively.

\section{Meal Pattern, within Meals Microstructure and Return Map Analyses}

To determine the mode of action by which intra-CeA PACAP produces anorexia, a microstructure analysis of food intake was performed. Time course analyses indicated that the incremental anorexia of $1 \mu \mathrm{g}$ of PACAP (highest effective dose in the free feeding experiments) was greatest during the first half of the dark cycle, so subsequent analyses were limited to the first 6 post-treatment hours. As shown in Figure 3, PACAP decreased how much food was eaten in a meal (Figure $3 \mathrm{a}, Z=2.38, P \leqslant 0.02$ ), but not the frequency of meal-taking (Figure $3 \mathrm{~b}, Z=0.31$, NS) or the time between meals (Figure 3c, $Z=0.14$, NS). Even though intra-CeA PACAP-treated rats ate smaller meals, their meals were of normal duration (Figure $3 \mathrm{~d}, Z=0.56$, NS). Within-meal microstructure analysis revealed that intra-CeA PACAP slowed the rate of eating within meals, as revealed by a significant increase of the IFIs (Figure $3 e, Z=2.38, P \leqslant 0.02$ ) and by a rightward shift of the frequency histogram (Figure 3i). Intra-CeA PACAP also significantly increased the variability in the rate of eating within meals as reflected by an increased entropy (Figure $3 \mathrm{f}, Z=2.38, P \leqslant 0.02$ ). Skewness and kurtosis were not affected by drug treatment (Figure 3g, $Z=0.56$, NS.; Figure $3 \mathrm{~h}, Z=0.56$, NS, respectively). Return map analysis of within-meal IFIs further showed that intra-CeA PACAP increased the irregularity of feeding, as reflected in a greater diffuseness of the withinmeal spread compared with vehicle (Figure $3 \mathrm{j})$. PACAP also decreased the amount of water rats $\operatorname{drank}(Z=2.38, p \leqslant 0.05$, 

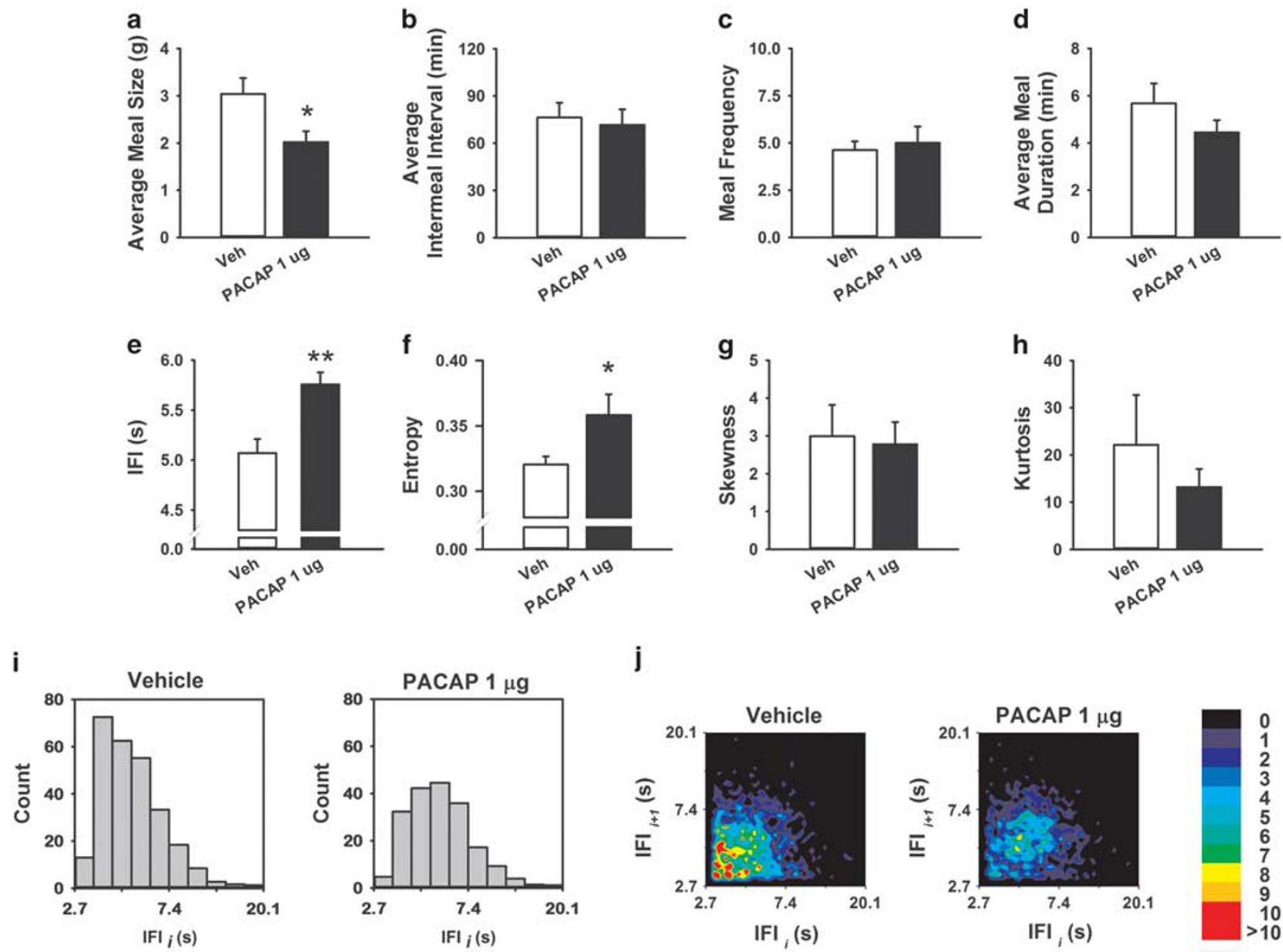

j

Figure 3 Effects of bilateral microinfusion of PACAP $(0-\mid \mu$ g per rat) in the central nucleus of the amygdala (CeA) on meal pattern parameters ((a), average meal size, (b) average inter-meal interval, (c) meal frequency, and (d) average meal duration), and within-meal microstructure parameters ((e) average interfeeding intervals (IFIs), (f) entropy, (g) skewness, and (h) kurtosis). (i) Frequency histograms of the In-transformed duration of consecutive, intra-meal IFIs from all subjects, normalized for the total number of subjects. (j) Return map normalized probability density plots representing successive IFls from all subjects. Increasing gray-scale intensity (from white to black) (or color intensity from black to red in the color figure) represents increasing probabilities (from 0 to 10 ) of successive eating events and, therefore, increased regularity of eating from pellet-to-pellet occurring at the corresponding IFI duration. For representative purposes, histograms and return map graphs depict the window $e^{1}$ to $e^{3}$, or $2.7-20.1 \mathrm{~s} . * 0 \leqslant 0.05, * * 0 \leqslant 0.01$ vs vehicle group. PACAP, pituitary adenylate cyclase-activating polypeptide.

$3.7 \pm 0.4$ vs $2.3 \pm 0.3$, Veh vs PACAP, respectively, data not shown), as previously shown.

\section{Administration of PACAP into the CeA Does Not Affect Motor Activity}

As shown in Table 1, bilateral PACAP administration into the CeA did not affect motor activity in the 12-h observation period (PACAP: $\mathrm{F}(2,16)=0.72$, NS; Time: $\mathrm{F}(3,24)=185.12$, $p \leqslant 0.001$; PACAP $\times$ time: $\mathrm{F}(6,48)=1.25, \mathrm{NS})$, confirming the specificity of the anorectic effect observed.

\section{The MC3/MC4 Receptor Antagonist SHU 9119 Blocks PACAP-induced Anorexia and Body Weight Loss}

Administration of the MC3/MC4 receptor antagonist SHU $9119(0.032 \mu \mathrm{g}$ per rat $)$ in the CeA blocked PACAP-induced anorexia (PACAP: $\mathrm{F}(1,10)=7.95, p \leqslant 0.05$; antagonist: $\mathrm{F}$ $(1,10)=6.01, p \leqslant 0.05 ;$ PACAP $\times$ antagonist: $\mathrm{F}(1,10)=27.55$, $p \leqslant 0.001)$ in the 24 -h post-administration period, without affecting food intake per se, as shown in Figure 4a. The MC3/MC4 receptor antagonist SHU 9119 also blocked PACAP-induced body weight loss ((PACAP: $F(1,10)=$ $12.82, p \leqslant 0.05$; antagonist: $\mathrm{F}(1,10)=6.60, p \leqslant 0.05$; PACAP $\times$ antagonist: $\mathrm{F}(1,10)=50.70, p \leqslant 0.0001)$, again without having any effect per se (Figure $4 \mathrm{~b}$ ).

\section{The TrkB Inhibitor k252a Blocks PACAP-induced Anorexia and Body Weight Loss}

Administration of the $\operatorname{TrkB}$ inhibitor $\mathrm{k} 252 \mathrm{a}(0.11 \mu \mathrm{g}$ per rat) in the CeA also blocked PACAP-induced anorexia (PACAP: $\mathrm{F}(1,8)=31.5, \quad p \leqslant 0.05 ;$ antagonist: $\mathrm{F}(1,8)=15.4, \quad p \leqslant 0.05$; PACAP $\times$ antagonist: $F(1,8)=25.03, p \leqslant 0.01)$ in the $24-h$ post-administration period, without affecting food intake per se, as shown in Figure 4c. In addition, k252a blocked PACAP-induced body weight loss after $24 \mathrm{~h}$ with a considerable trend toward significance (PACAP: $\mathrm{F}(1,8)=65.70$, 
Table I Effects of Bilateral Microinfusion of PACAP (0, I $\mu \mathrm{g}$ Per Rat) in the Central Nucleus of the Amygdala (CeA) on 12-h Motor Activity (Dark Cycle)

\begin{tabular}{|c|c|c|c|}
\hline & Vehicle & PACAP $0.3 \mu \mathrm{g}$ & PACAP I $\mu \mathrm{g}$ \\
\hline \multicolumn{4}{|l|}{ I h } \\
\hline Mean & 2070.8 & 2771.4 & 2973.6 \\
\hline SEM & 173.4 & 271.1 & 228.4 \\
\hline \multicolumn{4}{|l|}{$3 h$} \\
\hline Mean & 5217.2 & 5998.2 & 5504.0 \\
\hline SEM & 328.1 & 575.9 & 252.2 \\
\hline \multicolumn{4}{|l|}{$6 \mathrm{~h}$} \\
\hline Mean & 10821.3 & 10825.8 & 10523.8 \\
\hline SEM & 870.8 & 843.9 & 319.7 \\
\hline \multicolumn{4}{|l|}{$12 \mathrm{~h}$} \\
\hline Mean & 19735.8 & 21281.4 & 19744.0 \\
\hline SEM & | 435.6 & |532.| & | | | 4.0 \\
\hline
\end{tabular}

Data represent mean \pm SEM.

$p \leqslant 0.001$; antagonist: $\mathrm{F}(1,8)=2.65$, NS; PACAP $\times$ antagonist: $\mathrm{F}(1,8)=4.53, p=0.06)$ and without producing any effect per se (Figure $4 \mathrm{~d}$ ).

\section{The CRF Receptor Antagonist D-Phe-CRF(12-41) Does Not Block PACAP-Induced Anorexia and Body Weight Loss}

Administration of the CRF receptor antagonist D-Phe-CRF (12-41) $(0.5 \mu \mathrm{g}$ per rat) in the CeA did not affect PACAPinduced anorexia (PACAP: $\mathrm{F}(1,14)=25.97, p \leqslant 0.001$; antagonist: $\mathrm{F}(1,14)=0.14$, NS; PACAP $\times$ antagonist: $\mathrm{F}(1,14)=0.01$, NS in the 24-h post-administration period (Figure 4a). Moreover, PACAP-induced body weight loss was not affected by $\mathrm{D}-\mathrm{Phe}-\mathrm{CRF}(12-41)$, as shown in Figure 4b (PACAP: $\mathrm{F}(1,14)=12.96, \quad p \leqslant 0.05 ; \quad$ antagonist: $\mathrm{F}(1,14)=0.02, \quad \mathrm{NS}$; PACAP $\times$ antagonist: $\mathrm{F}(1,14)=0.12, \mathrm{NS})$.

\section{DISCUSSION}

The amygdala, a brain region traditionally studied for its role in fear and anxiety, also regulates ingestive behaviors, playing an important role in the emotional response to ingested food as well as in food preferences (Glass et al, 2000; Will et al, 2004). Although induction of anorexia is a well-documented effect of PACAP, the central sites underlying this phenomenon are poorly understood. These series of studies demonstrate that PACAP administration into the CeA, but not the BlA, dose-dependently promotes anorexia and body weight loss. Intra-CeA PACAP inhibits food intake by preferentially increasing satiation and lessening the maintenance of feeding rather than affecting satiety. Importantly, this hypophagia is not the result of a general reduction in activity. Finally, blockade of either melanocortin or TrkB receptors in the CeA prevents PACAP anorectic effects. The results collectively suggest a role for the CeA PACAP/PAC1 receptor system in the regulation of appetite and energy homeostasis.

PACAP microinfused into the CeA of non-restricted rats dose-dependently reduced food intake and body weight gain at doses very similar to those that elicit hypophagia at hypothalamic sites and with a similar duration of action (Resch et al, 2011; Resch et al, 2013). On the other hand, PACAP microinfused into the closely located BlA had no effect on either parameter, confirming specificity of action. The effect of intra-CeA PACAP incrementally lasted for $6 \mathrm{~h}$, with the highest dose still reducing intake at the 24-h time point. Interestingly, the hypophagia was not evident at the 1 -h time point, suggesting a delayed onset of action; we speculate that PACAP-induced changes in gene expression may, therefore, mediate its effects on food intake after intra$\mathrm{CeA}$ administration.

The microstructure results show that PACAP administrated into the CeA profoundly affected the structure of feeding within meals, decreasing the rate and the regularity of feeding, effects consistent with an increased satiation. Conversely, PACAP did not influence satiety as meals were normal in length, and post-meal interval and meal frequency were unaltered. Thus, the primary anorectic mode of action of PACAP was to inhibit sustained eating within meals rather than inhibiting the reinitiation of feeding between meals. The findings that PACAP slows feeding within meals without affecting number of meals also suggests that PACAP does not induce malaise, as malaise is generally associated with a reduction of the number of meals and an increase in the inter-meal interval (Blundell et al, 1985). We chose to use an FR1 schedule of reinforcement to reproduce in the operant boxes conditions that closely resembled those in the home cage (ad libitum consumption), which require a very low effort; the microstructure analysis used in this study is a well-established procedure, which has been extensively employed to study meal pattern following pharmacological treatments (Zorrilla et al, 2005). Although direct comparisons are difficult to make given the different microstructure definitions, the anorectic mechanism of PACAP when microinfused into the CeA appears to be analogous to that resulting from PACAP microinfusion into the paraventricular, but not the $\mathrm{VMH}$, nucleus of the hypothalamus (Resch et al, 2013). Interestingly, a similar modality of anorectic action has been shown for MC4R activation, as MC4R agonism reduces meal size but not meal frequency (Williams et al, 2002; Zheng et al, 2005). Remarkably, decreased eating rate and increased satiation are effects opposite to those which result from increasing food palatability (Cottone et al, 2007b). In the microstructure study, PACAP treatment also decreased water intake; this effect is in line with what has been reported for PACAP administration into the hypothalamus and the BNST (Chance et al, 1995; KochoSchellenberg et al, 2014).

Importantly, the lack of effect on motor activity attests that the reduction in food intake and the body weight loss induced by PACAP were not due to a general behavioral suppression, as already shown after administration of PACAP intracerebroventricularly as well as site-specifically in other brain areas (Kocho-Schellenberg et al, 2014; Mounien et al, 2009; Resch et al, 2011). Alternative explanations for the anorectic effect of intra-CeA PACAP should, however, be 

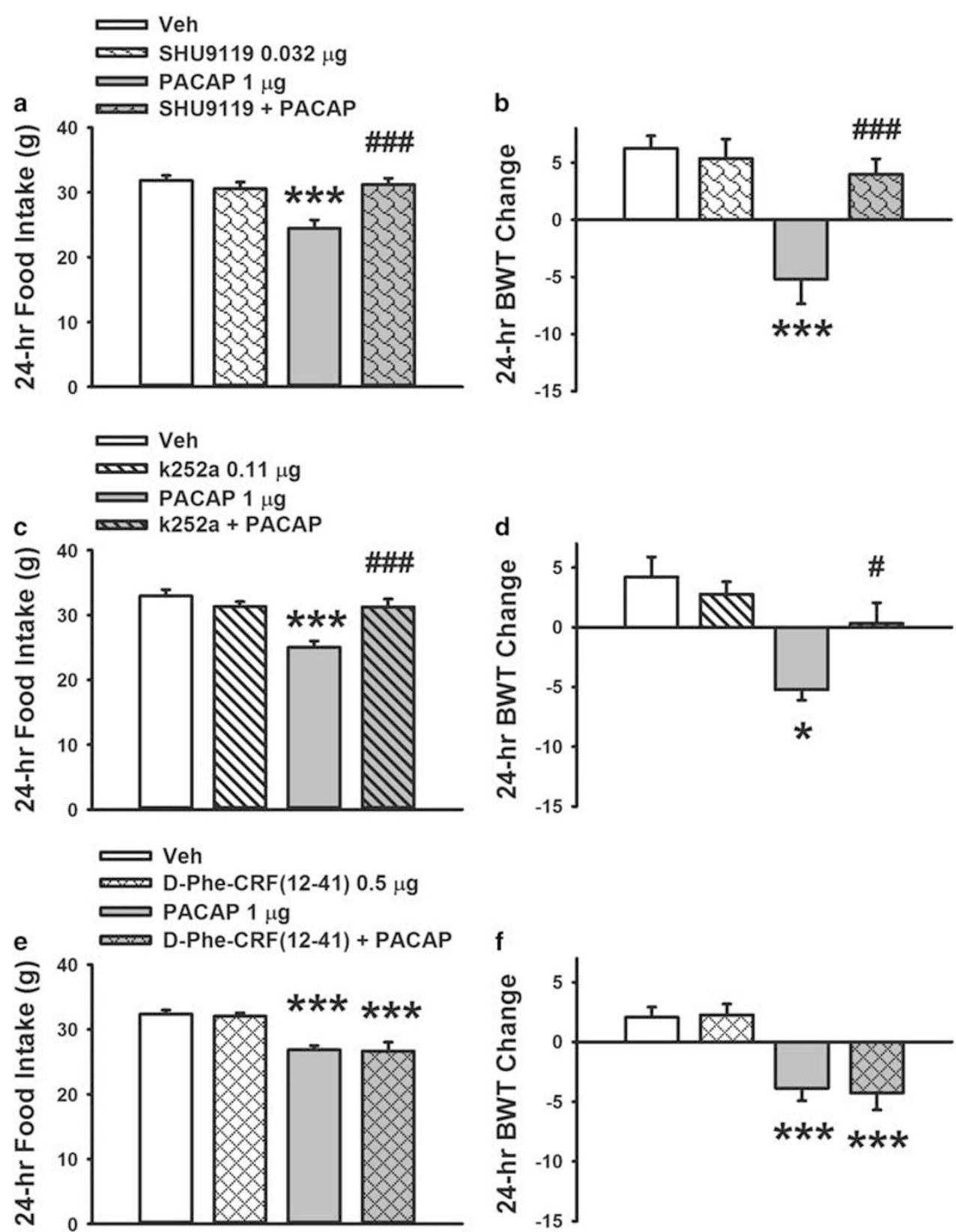

Figure 4 Effects of bilateral microinfusion in the central nucleus of the amygdala (CeA) of either the MC3/MC4 receptor antagonist SHU $9119(0,0.032 \mu \mathrm{g}$ per rat) (a, b) or the TrkB inhibitor k252a (0.II $\mu \mathrm{g}$ per rat) (c, d), or the CRFI/CRF2 receptor antagonist D-Phe-CRF(I2-4I) (0.5 $\mu$ g per rat) (e, f), together with PACAP $(0, I \mu$ g per rat), on ( $a, c$ and e) 24 - $h$ food intake and ( $b, d$ and $f$ ) body weight change. Data represent mean \pm SEM. * $p \leqslant 0.05$, **** $p \leqslant 0.00$ I vs

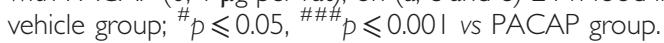

considered. The CeA is well-known for promoting anxiety and fear, and the PACAP/PAC1 system has been shown to mediate the behavioral, autonomical, and endocrine responses to stress (Dore et al, 2013; Stroth et al, 2011). This raises the possibility that the observed feeding inhibition after intra-CeA administration of PACAP could be the result of the promotion of anxiety. However, several lines of evidence suggest otherwise. First, PACAP was administered in a familiar environment, not a novel one for the rats (home cage), and it did not reduce locomotion; second, the anorectic effect was not reversed by the CRF receptor antagonist, which instead reverses the anxiogenic effect of i.c.v. PACAP
(Dore et al, 2013) and has been shown to reverse the anxiogenic effects of stress and drug withdrawal when administered directly into the CeA (Heinrichs et al, 1995; Rassnick et al, 1993); third, the time-course of the anorectic effect of intra-CeA PACAP (ie, the delayed onset) is not in line with the fast onset of anxiety following intra-CeA PACAP administration (evident already after $30 \mathrm{~min}$, unpublished observations and Missig et al, (2014)). These data suggest that the anorectic effect of intra-CeA PACAP is unlikely to be a result of increased anxiety.

One limitation of the present study is that it involves the exogenous administration of the peptide. Despite the lack of 
small molecule PACAP receptor antagonists, follow-up studies will need to prove the role of the endogenous PACAP system in feeding behavior by using pharmacological antagonists or viral knockdown of PACAP and/or PAC1.

By inhibiting melanocortin receptors, we were able to examine their contribution to PACAP-mediated decreases in food intake in the $\mathrm{CeA}$; indeed, microinfusion of the MC3R/MC4R antagonist SHU9119 successfully blocked the hypophagia induced by intra-CeA PACAP. The melanocortin system, and in particular MC4R, has a key role in the regulation of appetite and energy balance (Seeley et al, 2004). Mutations in the human MC4R have been associated with obesity and the deletion of MC3R/MC4R in mice leads to hyperphagia and obesity (Huszar et al, 1997). Furthermore, infusion of MC4R agonists decreases food intake, whereas antagonism results in increased food intake (Rossi et al, 1998). Interestingly, alpha melanocyte-stimulating hormone $(\alpha-\mathrm{MSH})$ and the MC4R are abundantly expressed not only in hypothalamic nuclei but also in the amygdala and, when administered into the CeA, MC4R agonists inhibit feeding (Boghossian et al, 2010; Kask and Schioth, $2000 \mathrm{~b}$ ), suggesting a role for CeA MC4R in the regulation of feeding.

Our results showing that the anorexia observed following PACAP receptor activation in the $\mathrm{CeA}$ is dependent on the activation of melanocortin receptors are in line with previous reports suggesting a strong relationship between the PACAP and the melanocortin systems, with the PACAP system regulating the activity of POMC neurons. PACAP, but not VIP, has been shown to increase POMC mRNA and $\alpha$-MSH content in the hypothalamus (Mounien et al, 2006). PACAP administration increases the activation of POMC neurons as well as POMC and MC4R mRNA levels in the arcuate nucleus, and the pretreatment with a melanocortin receptor antagonist reduces the effect of i.c.v. PACAP on food consumption in mice (Mounien et al, 2009). In addition, the melanocortin system has been shown to mediate the central effects of PACAP on thermogenic sympathetic and digestive parasympathetic outflow (Tanida and Mori, 2011). Therefore, based on our data, we speculate that PAC1 receptors are expressed presynaptically on POMC neuronal terminals to increase the release/synthesis of $\alpha-\mathrm{MSH} ; \alpha$-MSH would then act on MC4R within the CeA. Since de-afferentiation of the arcuate nucleus of the hypothalamus results in a dramatic reduction of $\alpha-\mathrm{MSH}$ immunoreactivity in the amygdala (Eskay et al, 1979), it is likely that the source of the CeA $\alpha$-MSH is indeed hypothalamic. Finally, the involvement of MC3R in the observed effects is highly unlikely considering the very low (undetectable by real time PCR) levels of this receptor in the $\mathrm{CeA}$ (personal observations).

Here we demonstrate that the anorectic effect of intra-CeA PACAP is mediated also by $\operatorname{TrkB}$ receptors, suggesting an increased release or synthesis of BDNF in the CeA following PACAP administration. Considerable evidence has shown that BDNF is involved in feeding and energy homeostasis via its TrkB receptor. Central infusion of BDNF suppresses appetite and reduces body weight in rodents; manipulations of the BDNF gene in animals as well as the study of BDNF gene mutations in humans have confirmed a pivotal role of the BDNF-TrkB system in feeding and weight control (Takei et al, 2014). However, while the majority of the reports have identified the hypothalamus as the main brain site responsible for the effects of BDNF on food intake, work investigating the function of the BDNF/TrkB system in the amygdala has only focused on anxiety and fear. Therefore, even though the antagonist used in this study is not selective for the different types of Trk receptors, considering the available literature our work would suggest that the BDNF/TrkB system in the $\mathrm{CeA}$ has a role of regulating food intake. However, further studies using a knockdown of TrkB and/or BDNF antibodies are needed to definitively prove a BDNF/TrkB involvement $v s$ other growth factors activating Trk receptors.

One interesting question is whether the melanocortin and the TrkB systems in the $\mathrm{CeA}$ are part of a single pathway activated by PACAP, or rather two independent, parallel pathways. In the $\mathrm{VMH}$, activation of MC4R has been shown to regulate $\mathrm{BDNF}$ levels and activity, suggesting that the $\mathrm{BDNF} / \mathrm{TrkB}$ pathway is downstream of the melanocortin MC4R (Xu et al, 2003). We speculate that a PACAP/ $\alpha-\mathrm{MSH} /$ $\mathrm{BDNF}$ pathway may exist in the $\mathrm{CeA}$ inhibiting feeding.

Interestingly, the reduction in food intake and the body weight loss induced by PACAP were not blocked by the CRF receptor antagonist D-Phe-CRF(12-41), suggesting a mechanism that does not involve local CRF receptor activation. Our results are consistent with previous reports showing the inability of CRF receptor antagonists to block the hypophagia induced by i.c.v. PACAP (Dore et al, 2013).

In this study, we did not directly ascertain that the anorectic effects of PACAP are mediated by the PACAP-selective PAC1 receptor, rather than VPAC1/VPAC2 receptors. The hypophagia produced by PACAP administered within the hypothalamus is abolished by PAC1 antagonism, whereas pretreatment with VPAC antagonist has no effect (Mounien et al, 2009; Resch et al, 2013). These data, together with the observation that VIP does not reduce food intake (Mounien et al, 2009), strongly suggest the exclusive involvement of PAC1 receptors in the regulation of food intake.

Medium/high densities of PACAP fibers and PAC1 receptors are present throughout the CeA (Joo et al, 2004; Piggins et al, 1996), suggesting that PACAP in this brain area may be released following anorexigenic stimuli, such as satiety. Whether the source of PACAP into the CeA is local or not is unclear; a recent study has shown that lesions of the lateral parabrachial nucleus significantly attenuate PACAP immunoreactivity in the $\mathrm{CeA}$, suggesting that projections from this region could be responsible for a large part of the PACAP released in the CeA (Missig et al, 2014). This hypothesis is consistent with the observation that the stimulation of calcitonin gene related peptide-positive neurons in the parabrachial nucleus projecting to the $\mathrm{CeA}$, which have been shown to co-express PACAP, inhibits feeding (Carter et al, 2013). Furthermore, we can hypothesize that the PACAP system may interfere with the function of the CeA recently described by the Berridge's group of enhancing and narrowing incentive motivation to pursue a specific reward (Robinson et al, 2014).

In summary, we show that the CeA is a key brain site for the anorectic effects of PACAP and that PACAP preferentially lessens the maintenance of feeding in rats. We finally demonstrate that PACAP in the CeA exerts its anorectic effects via local melanocortin and TrKB systems. These results suggest that the PACAP system of the CeA is an important regulator of appetite and energy homeostasis. 


\section{FUNDING AND DISCLOSURE}

This publication was made possible by grants \# MH093650, MH091945, and DA030425 from the National Institute of Health, by the Peter McManus Trust, the Peter Paul Career Development Professorship (PC) and Boston University's Undergraduate Research Opportunities Program (UROP). The authors declare no conflict of interest.

\section{ACKNOWLEDGMENTS}

We thank Diane Tang, Carlos Santiago and Stephen St Cyr for technical assistance, Andrew Kim and Jeffrey Santos for editorial assistance.

\section{REFERENCES}

Balthasar N, Dalgaard LT, Lee CE, Yu J, Funahashi H, Williams T et al (2005). Divergence of melanocortin pathways in the control of food intake and energy expenditure. Cell 123: 493-505.

Blasio A, Steardo L, Sabino V, Cottone P (2014). Opioid system in the medial prefrontal cortex mediates binge-like eating. Addict Biol 19: 652-662.

Blouet C, Jo YH, Li X, Schwartz GJ (2009). Mediobasal hypothalamic leucine sensing regulates food intake through activation of a hypothalamus-brainstem circuit. J Neurosci 29: 8302-8311.

Blundell JE, Rogers PJ, Hill AJ (1985). Behavioural structure and mechanisms of anorexia: calibration of natural and abnormal inhibition of eating. Brain Res Bull 15: 371-376.

Boghossian S, Lemmon K, Park M, York DA (2009). High-fat diets induce a rapid loss of the insulin anorectic response in the amygdala. Am J Physiol Regul Integr Comp Physiol 297: R1302-R1311.

Boghossian S, Park M, York DA (2010). Melanocortin activity in the amygdala controls appetite for dietary fat. Am J Physiol Regul Integr Comp Physiol 298: R385-R393.

Butler AA, Cone RD (2003). Knockout studies defining different roles for melanocortin receptors in energy homeostasis. Ann NY Acad Sci 994: 240-245.

Carter ME, Soden ME, Zweifel LS, Palmiter RD (2013). Genetic identification of a neural circuit that suppresses appetite. Nature 503: 111-114.

Chance WT, Thompson H, Thomas I, Fischer JE (1995). Anorectic and neurochemical effects of pituitary adenylate cyclase activating polypeptide in rats. Peptides 16: 1511-1516.

Cheng CY, Chu JY, Chow BK (2011). Central and peripheral administration of secretin inhibits food intake in mice through the activation of the melanocortin system. Neuropsychopharmacology 36: 459-471.

Cottone P, Sabino V, Nagy TR, Coscina DV, Zorrilla EP (2007a). Feeding microstructure in diet-induced obesity susceptible versus resistant rats: central effects of urocortin 2. J Physiol 583(Pt 2): 487-504.

Cottone P, Sabino V, Steardo L, Zorrilla EP (2007b). FG 7142 specifically reduces meal size and the rate and regularity of sustained feeding in female rats: evidence that benzodiazepine inverse agonists reduce food palatability. Neuropsychopharmacology 32: 1069-1081.

Cottone P, Wang X, Park JW, Valenza M, Blasio A, Kwak J et al (2012). Antagonism of sigma-1 receptors blocks compulsivelike eating. Neuropsychopharmacology 37: 2593-2604.

Dekhuijzen AJ, Bagust J (1996). Analysis of neural bursting: nonrhythmic and rhythmic activity in isolated spinal cord. J Neurosci Methods 67: 141-147.

Dore R, Iemolo A, Smith KL, Wang X, Cottone P, Sabino V (2013). $\mathrm{CRF}$ mediates the anxiogenic and anti-rewarding, but not the anorectic effects of PACAP. Neuropsychopharmacology 38: 2160-2169.

Erb S, Stewart J (1999). A role for the bed nucleus of the stria terminalis, but not the amygdala, in the effects of corticotropinreleasing factor on stress-induced reinstatement of cocaine seeking. J Neurosci 19: RC35.

Eskay RL, Giraud P, Oliver C, Brown-Stein MJ (1979). Distribution of alpha-melanocyte-stimulating hormone in the rat brain: evidence that alpha-MSH-containing cells in the arcuate region send projections to extrahypothalamic areas. Brain Res 178: 55-67.

Funk CK, O'Dell LE, Crawford EF, Koob GF (2006). Corticotropinreleasing factor within the central nucleus of the amygdala mediates enhanced ethanol self-administration in withdrawn, ethanol-dependent rats. J Neurosci 26: 11324-11332.

Glass MJ, Billington CJ, Levine AS (2000). Naltrexone administered to central nucleus of amygdala or PVN: neural dissociation of diet and energy. Am J Physiol Regul Integr Comp Physiol 279: R86-R92.

Heinrichs SC, Menzaghi F, Schulteis G, Koob GF, Stinus L (1995). Suppression of corticotropin-releasing factor in the amygdala attenuates aversive consequences of morphine withdrawal. Behav Pharmacol 6: 74-80.

Huszar D, Lynch CA, Fairchild-Huntress V, Dunmore JH, Fang Q, Berkemeier LR et al (1997). Targeted disruption of the melanocortin-4 receptor results in obesity in mice. Cell 88: 131-141.

Iemolo A, Blasio A St, Cyr SA, Jiang F, Rice KC, Sabino V et al (2013). CRF-CRF1 receptor system in the central and basolateral nuclei of the amygdala differentially mediates excessive eating of palatable food. Neuropsychopharmacology 38: 2456-2466.

Joo KM, Chung YH, Kim MK, Nam RH, Lee BL, Lee KH et al (2004). Distribution of vasoactive intestinal peptide and pituitary adenylate cyclase-activating polypeptide receptors (VPAC1, VPAC2, and PAC1 receptor) in the rat brain. J Comp Neurol 476: 388-413.

Kalra SP, Dube MG, Pu S, Xu B, Horvath TL, Kalra PS (1999). Interacting appetite-regulating pathways in the hypothalamic regulation of body weight. Endocrine Rev 20: 68-100.

Kask A, Rago L, Wikberg JE, Schioth HB (2000a). Differential effects of melanocortin peptides on ingestive behaviour in rats: evidence against the involvement of $\mathrm{MC}(3)$ receptor in the regulation of food intake. Neurosci Lett 283: 1-4.

Kask A, Schioth HB (2000b). Tonic inhibition of food intake during inactive phase is reversed by the injection of the melanocortin receptor antagonist into the paraventricular nucleus of the hypothalamus and central amygdala of the rat. Brain Res 887: 460-464.

King BM, Rossiter KN, Cook JT, Sam HM (1997). Amygdaloid lesion-induced obesity in rats in absence of finickiness. Physiol Behav 62: 935-938.

King BM, Rossiter KN, Stines SG, Zaharan GM, Cook JT, Humphries MD et al (1998). Amygdaloid-lesion hyperphagia: impaired response to caloric challenges and altered macronutrient selection. Am J Physiol 275(2 Pt 2): R485-R493.

Kishi T, Elmquist JK (2005). Body weight is regulated by the brain: a link between feeding and emotion. Mol Psychiatry 10: 132-146.

Kocho-Schellenberg M, Lezak KR, Harris OM, Roelke E, Gick N, Choi I et al (2014). PACAP in the BNST produces anorexia and weight loss in male and female rats. Neuropsychopharmacology 39: 1614-1623.

Leibowitz SF, Wortley KE (2004). Hypothalamic control of energy balance: different peptides, different functions. Peptides 25: 473-504.

Missig G, Roman CW, Vizzard MA, Braas KM, Hammack SE, May V (2014). Parabrachial nucleus (PBn) pituitary adenylate cyclase activating polypeptide (PACAP) signaling in the amygdala: implication for the sensory and behavioral effects of pain. Neuropharmacology 86: 38-48. 
Morton GJ, Cummings DE, Baskin DG, Barsh GS, Schwartz MW (2006). Central nervous system control of food intake and body weight. Nature 443: 289-295.

Mounien L, Bizet P, Boutelet I, Gourcerol G, Fournier A, Vaudry H et al (2006). Pituitary adenylate cyclase-activating polypeptide directly modulates the activity of proopiomelanocortin neurons in the rat arcuate nucleus. Neuroscience 143: 155-163.

Mounien L, Do Rego JC, Bizet P, Boutelet I, Gourcerol G, Fournier A et al (2009). Pituitary adenylate cyclase-activating polypeptide inhibits food intake in mice through activation of the hypothalamic melanocortin system. Neuropsychopharmacology 34: 424-435.

Mountjoy KG, Mortrud MT, Low MJ, Simerly RB, Cone RD (1994). Localization of the melanocortin-4 receptor (MC4-R) in neuroendocrine and autonomic control circuits in the brain. $\mathrm{Mol}$ Endocrinol 8: 1298-1308.

Ou LC, Gean PW (2006). Regulation of amygdala-dependent learning by brain-derived neurotrophic factor is mediated by extracellular signal-regulated kinase and phosphatidylinositol-3kinase. Neuropsychopharmacology 31: 287-296.

Ou LC, Yeh SH, Gean PW (2010). Late expression of brain-derived neurotrophic factor in the amygdala is required for persistence of fear memory. Neurobiol Learn Mem 93: 372-382.

Piggins HD, Stamp JA, Burns J, Rusak B, Semba K (1996). Distribution of pituitary adenylate cyclase activating polypeptide (PACAP) immunoreactivity in the hypothalamus and extended amygdala of the rat. J Comp Neurol 376: 278-294.

Primeaux SD, York DA, Bray GA (2006). Neuropeptide Y administration into the amygdala alters high fat food intake. Peptides 27: 1644-1651.

Rassnick S, Heinrichs SC, Britton KT, Koob GF (1993). Microinjection of a corticotropin-releasing factor antagonist into the central nucleus of the amygdala reverses anxiogenic-like effects of ethanol withdrawal. Brain Res 605: 25-32.

Resch JM, Boisvert JP, Hourigan AE, Mueller CR, Yi SS, Choi S (2011). Stimulation of the hypothalamic ventromedial nuclei by pituitary adenylate cyclase-activating polypeptide induces hypophagia and thermogenesis. Am J Physiol Regul Integr Comp Physiol 301: R1625-R1634.

Resch JM, Maunze B, Gerhardt AK, Magnuson SK, Phillips KA, Choi S (2013). Intrahypothalamic pituitary adenylate cyclaseactivating polypeptide regulates energy balance via site-specific actions on feeding and metabolism. Am J Physiol Endocrinol Metab 305: E1452-E1463.

Robinson MJ, Warlow SM, Berridge KC (2014). Optogenetic excitation of central amygdala amplifies and narrows incentive motivation to pursue one reward above another. J Neurosci 34: 16567-16580.

Rossi M, Kim MS, Morgan DG, Small CJ, Edwards CM, Sunter D et al (1998). A C-terminal fragment of Agouti-related protein increases feeding and antagonizes the effect of alpha-melanocyte stimulating hormone in vivo. Endocrinology 139: 4428-4431.
Sabino V, Cottone P, Steardo L, Schmidhammer H, Zorrilla EP (2007). 14-Methoxymetopon, a highly potent mu opioid agonist, biphasically affects ethanol intake in Sardinian alcoholpreferring rats. Psychopharmacology (Berl) 192: 537-546.

Seeley RJ, Drazen DL, Clegg DJ (2004). The critical role of the melanocortin system in the control of energy balance. Annu Rev Nutr 24: 133-149.

Stroth N, Holighaus Y, Ait-Ali D, Eiden LE (2011). PACAP: a master regulator of neuroendocrine stress circuits and the cellular stress response. Ann NY Acad Sci 1220: 49-59.

Szucs A, Pinto RD, Rabinovich MI, Abarbanel HD, Selverston AI (2003). Synaptic modulation of the interspike interval signatures of bursting pyloric neurons. J Neurophysiol 89: 1363-1377.

Takei N, Furukawa K, Hanyu O, Sone H, Nawa H (2014). A possible link between BDNF and mTOR in control of food intake. Front Psychol 5: 1093.

Tanida M, Mori M (2011). Nesfatin-1 stimulates renal sympathetic nerve activity in rats. Neuroreport 22: 309-312.

Touzani K, Taghzouti K, Velley L (1997). Increase of the aversive value of taste stimuli following ibotenic acid lesion of the central amygdaloid nucleus in the rat. Behav Brain Res 88: 133-142.

Vaudry D, Falluel-Morel A, Bourgault S, Basille M, Burel D, Wurtz O et al (2009). Pituitary adenylate cyclase-activating polypeptide and its receptors: 20 years after the discovery. Pharmacol Rev 61: 283-357.

Velazquez-Sanchez C, Ferragud A, Moore CF, Everitt BJ, Sabino V, Cottone P (2014). High trait impulsivity predicts food addictionlike behavior in the rat. Neuropsychopharmacology 39: 2463-2472.

Will MJ, Franzblau EB, Kelley AE (2004). The amygdala is critical for opioid-mediated binge eating of fat. Neuroreport 15: 1857-1860.

Williams DL, Grill HJ, Weiss SM, Baird JP, Kaplan JM (2002). Behavioral processes underlying the intake suppressive effects of melanocortin 3/4 receptor activation in the rat. Psychopharmacology (Berl) 161: 47-53.

Woods SC, Seeley RJ, Porte D Jr, Schwartz MW (1998). Signals that regulate food intake and energy homeostasis. Science 280: $1378-1383$

$\mathrm{Xu} \mathrm{B}$, Goulding EH, Zang K, Cepoi D, Cone RD, Jones $\mathrm{KR}$ et al (2003). Brain-derived neurotrophic factor regulates energy balance downstream of melanocortin-4 receptor. Nat Neurosci 6: 736-742.

Zheng H, Patterson LM, Phifer CB, Berthoud HR (2005). Brain stem melanocortinergic modulation of meal size and identification of hypothalamic POMC projections. Am J Physiol Regul Integr Comp Physiol 289: R247-R258.

Zorrilla EP, Inoue K, Fekete EM, Tabarin A, Valdez GR, Koob GF (2005). Measuring meals: structure of prandial food and water intake of rats. Am J Physiol Regul Integr Comp Physiol 288: R1450-R1467.

Supplementary Information accompanies the paper on the Neuropsychopharmacology website (http://www.nature.com/npp) 